\title{
LA SOCIEDAD CIVIL Y LOS CAMINOS (INCIERTOS) DE LA CIUDADANÍA*
}

\author{
Vera Telles**
}

¿Qué posibilidades hay, en Brasil, de construir un orden de vida justo? ¿Cómo universalizar los derechos en una sociedad no sólo desigual sino también muy diferenciada y multifacética en sus contradicciones? Ésa es una pregunta crucial en estos tiempos de crisis, en los cuales los destinos del país están siendo decididos en una encrucijada de alternativas inciertas, diseñadas entre el legado de una tradición autoritaria y excluyente y las transformaciones en curso en el mundo contemporáneo. En términos más inmediatos, es una cuestión que se refiere a los aspectos tal vez más desconcertantes del Brasil actual. En los años 80 , los movimientos sociales se organizaron, los sindicatos se fortalecieron y las aspiraciones por una sociedad más justa e igualitaria se concretaron en la reivindicación de derechos, se proyectaron en el escenario público, dejaron sus marcas en conquistas importantes en la Constitución de 1988 y se tradujeron en la construcción de sujetos políticos hoy reconocidos como interlocutores legítimos en el juego político nacional. Esta década, vivida bajo el signo de la esperanza democrática, se cerró, sin embargo, con el espectáculo de una pobreza tal vez jamás vista en nuestra historia republicana. Entramos en los años 90 viviendo la paradoja de una democracia consolidada en sus instituciones y en las reglas formales del juego político, pero que convive cotidianamente con la violencia, la violación de los derechos humanos y la incivilidad en las relaciones sociales.

Esa paradoja está en el centro del debate actual. Porque además de los consabidos límites de la democracia en una sociedad de tradición autoritaria, es el carácter mismo de la legalidad democrática construida lo que está en discusión. Una legalidad truncada, dice O’Donnell (1993), que garantiza los derechos políticos democráticos, pero no consigue fortalecer la ley, los derechos y la justicia en el conjunto heterogéneo de la vida social, sustraídos por circuitos paralelos de poder que borran la dimensión pública de la ciudadanía, reintroducen la violencia y la arbitrariedad en la esfera de las relaciones privadas, de clase, de género o etnia y hacen al Estado cada vez más ineficaz en hacer efectiva sus propias regulaciones. Para Wanderley Guillherme dos Santos (1993), el problema hunde sus raíces en la tradición corporativa brasileña, que generó una institucionalidad

Traducción del portugués: Ana Inés López-Accotto

(*) Este artículo fue publicado en Sâo Paulo em Perspectiva, 8(2)1994

(**) Profesora del Departamento de Sociología de la Universidad de Sao Paulo. Directora de PólisInstituto de Estudios, Formación y Asesoría en Políticas Sociales. incapaz de procesar los conflictos emergentes y producir un sentido de orden público como valor y referencia de una cultura cívica democrática. El resultado es un híbrido institucional que asocia "el confinamiento regulado de la ciudadanía" y un hobbesianismo social, en el que imperan la violencia como modo rutinario de resolución de conflictos intersubjetivos y el comportamiento depredatorio que, en estos tiempos de crisis e inseguridad, se vienen generalizando en la sociedad brasileña. Exageraciones aparte, ambos autores llaman la atención hacia la importancia de la ley y de las instituciones en el ordenamiento de la vida social. Ambos reclaman, con razón, la construcción democrática de un orden público capaz de garantizar los principios liberales clásicos de la igualdad y de la justicia. Mientras tanto, la posibilidad de ese orden público parece estar siendo erosionado por las transformaciones en curso en el mundo contemporáneo.

Y ese es otro foco del debate actual, que pone en cuestión los rumbos de una modernización que integra al país en los circuitos globalizados de la economía sin que hayan sido realizadas las tareas clásicas de una modernidad, aunque sea incompleta. Esa es la cuestión discutida por Lechner (1990), para quien los países latinoamericanos están hoy atravesados por una antinomia de fondo, entre los imperativos de una modernización necesaria o inevitable y las exigencias normativas de la institucionalidad democrática, incapaz de integrar social y simbólicamente a una mayoría sin lugar en un orden económico que genera fragmentación y exclusión. Para José Eduardo Faria, la realidad de la pobreza y de la exclusión en el país (y en el mundo), al mismo tiempo que confiere actualidad y urgencia al tema de los derechos humanos, tiene lugar en el interior de un reordenamiento global de la economía que quita eficacia a la acción reguladora de los Estados nacionales, mina la (desde siempre limitada) capacidad del ordenamiento jurídico de garantizar e universalizar derechos y expulsa a muchos hacia fuera del imperio de la ley, dejándolos "a merced de las innumerables formas de violencia física y moral" (Faria, 1994:69)

El hecho es que, en el contexto de las transformaciones que afectan al Estado, a la economía y a la sociedad, las paradojas actuales se dibujan entre la fragmentación social generada por las tendencias contemporáneas del mercado y la incapacidad del ordenamiento legal-institucional vigente de garantizar los principios igualitarios de la ciudadanía. No por azar la complicada cuestión de las relaciones entre Estado y sociedad está en el centro del debate actual. En torno a ella se producen controversias y polémicas, proyectos distintos e incluso antagónicos sobre lo 
que se entiende o lo que se espera de una necesaria reforma del Estado, de la redefinición de su poder regulador y de sus relaciones con la sociedad civil. Esa discusión, más allá de las filigranas de argumentos y posiciones, llama la atención sobre la dimensión fundacional de la crisis actual. Más allá de los problemas de ingeniería institucional, es un debate que pone el foco en las cuestiones clásicas de los derechos, de la justicia social y de la igualdad. Cuestiones clásicas de un contrato social que ha de ser refundado, no en los términos del juramento de obediencia al poder -tampoco reducido a la sintaxis liberal de las reglas jurídicas que ordenan las relaciones privadas-, sino un contrato capaz de afirmar los derechos como principios reguladores de la vida social y que establezca los términos de una negociación y una interlocución posibles respecto a las reglas de equidad y a la medida de justicia que deben prevalecer en las relaciones sociales. Esa es una posibilidad que existe en el horizonte de la dinámica social contemporánea, en la que tienen lugar los problemas y desafíos actuales, pero también las señales de una sociedad civil emergente, construida a través de prácticas de representación y negociación de actores colectivos reconocidos en la legitimidad de sus intereses y de los derechos que reivindican. Esa dinámica social contiene tanto las posibilidades de dualización y nuevas injusticias, como las posibilidades de la consolidación de espacios públicos democráticos que afirmen los derechos como parámetros en el reordenamiento de la economía y de la sociedad.

Esa es la ambivalencia de los tiempos que corren. Especifica el sentido mismo de la crisis actual, más allá de sus circunstancias más o menos inmediatas. Hace referencia a un momento de indeterminación, en el que pierden vigencia reglas anteriores de ordenamiento de la vida social y aun son inciertos los rumbos de los cambios en curso. Pero ese es el terreno por excelencia de la invención política. Y al contrario de los que divisan en el Estado el polo exclusivo de construcción de un nuevo sentido de orden público garantizado por leyes e instituciones estatales, es desde el ángulo de la dinámica social como se determina la crisis actual, en razón de situaciones y problemas inéditos que escapan a los parámetros establecidos y subvierten fórmulas políticas conocidas. Como muestra José Eduardo Faria, en un contexto de crisis y cambios, acompañados de una profundización de las desigualdades y carencias sociales, el orden legal establecido va siendo minado en su poder de regulación frente a una heterogeneidad y complejidad de las estructuras sociales, de los intereses en juego, de las jerarquías de poder y de las arenas conflictivas, que escapan a los "tradicionales efectos de nivelación" producidos por la norma estatal (Faria, 1993: 120). Lo que está en negociación, enfatiza Faria, es precisamente la producción de un nueva racionalidad legal, que renuncie a la pretensión de una regulación exhaustiva y avasalladora de todos los procesos sociales, que confiera poder normativo a las prácticas de negociación y redefina la acción reguladora del Estado, dirigida no tanto a la tipificación y uniformización de comportamientos individuales, sino a la "coordinación de las diferentes formas de legalidades forjadas en el interior de los distintos subsistemas sociales" y a la intermediación en el juego conflictivo de los intereses, garantizando la certeza jurídica indispensable para la vida democrática y, también, un mínimo de paridad que compense o neutralice la asimetría de poder de los grupos políticos y sociales (Faria, 1993: 131-132).
En rigor, es en torno a las exigencias de una nueva institucionalidad donde las propuestas y alternativas distintas se confrontan en un debate público que pone en escena a actores colectivos en disputa. Más allá de la (pobre) retórica ideológica anti-Estado, ese es el terreno en el cual las propuestas de cuño neoliberal ganan plausibilidad y resonancia pública. Contra la rigidez de las normas estatales, proponen la desregulación del mercado, presentada como condición para una "modernidad" en sintonía con el Primer Mundo, pero que en realidad representa una tentativa de privatizar las relaciones sociales, por el rechazo de la mediación pública de los derechos e instituciones democráticas. Pero la sociedad civil, por su parte, va forjando alternativas a la reestructuración conservadora de la economía y de la sociedad. Los movimientos sociales, los sindicatos y las asociaciones civiles que, en estos tiempos de crisis, aparecieron en el escenario público nacional, además de expresar un potencial defensivo contra la tradición excluyente de la sociedad brasileña, llaman la atención sobre la posibilidad de construcción de mecanismos públicos (y plurales) de regulación de las relaciones sociales, regladas por el reconocimiento de los derechos y mediados por las categorías universales de igualdad y de justicia. Es a través del prisma de la sociedad civil, por lo tanto, desde donde se puede apostar por la "invención democrática" de una nueva gramática política, enraizada en el terreno conflictivo y siempre problemático de la vida social y abierta a las cuestiones inéditas que la dinámica social contemporánea está suscitando.

Ante todo se trata de una sociedad que está cambiando muy rápidamente, volviéndose cada vez más compleja, heterogénea y diferenciada: surgen nuevas separaciones que cruzan transversalmente la estructura de clase, deshacen identidades tradicionales, crean otras tantas y generan una pluralidad de intereses no siempre convergentes, cuando no conflictivos y excluyentes. Es una dinámica social compuesta por formas distintas de sociabilidad, algunas antiguas y otras nuevas, consecuencia de las rápidas transformaciones de la vida urbana, de la organización de la producción y del consumo; de nuevas jerarquías sociales, atravesadas por enormes disparidades de renta, de cultura, de valores y también de acceso a los mecanismos de representación y participación política; de diferencias en los usos de la ciudad, en los modos de establecimiento y movilidad en el espacio urbano y de acceso a los bienes materiales y simbólicos de una sociedad de consumo pujante, pero también extremadamente estratificada y excluyente; de diferentes y muy desiguales formas de integración en un mercado que se altera a ritmo acelerado, desestabilizando las posiciones consolidadas, deshaciendo jerarquías ocupacionales tradicionales y creando nuevas formas de estratificación y movilidad ocupacional.

Esa sociedad tan heterogénea como desigual, en que las diferencias son también y sobre todo diseñadas por el orden de las carencias acumuladas en el correr de los años, está generando una conflictividad inédita que atraviesa todas las dimensiones de la vida social. Muchos ya han señalado que esa conflictividad rompió los límites del "orden regulado" construido en los años 30 , erosionó la homogeneidad que se presuponía en los espacios tradicionales de representación y expresa las demandas colectivas que no encuentran lugar en el ordenamiento legal y en los procedimientos judiciales tradicionales, reabriendo el carácter dilemático de la relación entre legalidad y legitimidad. En el curso de quince años aproximadamente, en un contexto de democratización y generalización de la conciencia de derechos, 
esa disputa está produciendo una legalidad emergente a partir de formas negociadas de arbitraje de los intereses enfrentados, en la que se elabora -allí donde antes había un juego de fuerza bruta-, una jurisprudencia informal que opera con criterios de justicia sustantiva, reinterpreta principios de la ley y crea nuevos derechos. Expresando demandas sin respuesta en el derecho estatal, creando situaciones inéditas difícilmente homogeneizables en las formas de la ley, los conflictos sociales se están resolviendo, cada vez más, a través de prácticas de arbitraje que combinan la libre interpretación de los principios de la ley, la transgresión consentida de normales legales y la producción de "reglas de derecho" con una jurisdicción propia y localizada (Faria, 1989). Es una dinámica que algunos, correctamente o no, llaman postmoderna, en la que los procedimientos informales de arbitraje descolocan la tradicional centralidad y unidad del derecho estatal, generando una legalidad discontinua y fragmentaria, pero portadora de virtualidades inéditas para una ciudadanía ampliada, en la medida en que se abre al reconocimiento de nuevos derechos y a principios de justicia social (Farias, 1989).

Sin embargo, ese patrón emergente de conflictos también plantea cuestiones nuevas e imprevistas. Lo peculiar de los conflictos sociales contemporáneos es que escapan a los principios universales de equidad, desplazan el sentido clásico de una igualdad de identidad, para poner en acción la lógica diferenciada de los "derechos de las desigualdades" -derechos, como dice Ewald (1986), de las "discriminaciones positivas".

Asociados a contextos sociales particulares y específicos, los derechos reivindicados individualizan casos y situaciones no directamente conmensurables en el orden de sus necesidades, separaciones internas, relaciones de poder e injusticias a ser reparadas. Son derechos formulados en el terreno mismo de los conflictos, en los que la exigencia de justicia se refiere no tanto a la aplicación ecuánime de la ley, sino a las reglas de una equidad que restablezca equilibrios rotos, compense asimetrías de posiciones y defina el conjunto de prerrogativas y de garantías de los desiguales. En rigor, es la definición de esa regla de equidad la que estructura el campo de conflicto, en una dinámica que escapa a la lógica binaria de lo permitido y lo prohibido y evoca, por eso mismo, un arbitraje sobre lo que "es de derecho", que se abra a las prácticas de negociación y a la representación legitimada de los intereses enfrentados. Es en esos términos en los que se puede identificar en la dinámica política contemporánea, la construcción de un contrato social definido en las reglas pactadas del conflicto. Se trata de un contrato muy peculiar, que no se reduce al ordenamiento jurídico establecido, pues es plural y descentrado, regido por reglas inventadas y negociadas en una temporalidad propia, siempre particularizada y muchas veces inusitada, de los conflictos.

Al mismo tiempo, esa contractualidad informal pone en cuestión las difíciles relaciones entre las conquistas sociales y sus garantías, pues en el terreno cambiante del conflicto social, sus reglas están siempre sujetas a cuestionamientos y redefiniciones por la fuerza de las circunstancias que solapan consensos establecidos, descolocan equilibrios de fuerza y alteran las fronteras de las arenas organizadas de representación y negociación. La trayectoria reciente de los movimientos sociales está enteramente implicada en ello, en un esfuerzo muy desigual en sus resultados de inscribir nuevos derechos en el orden legal, lo que, en muchos casos, se tradujo en iniciativas convergentes en el sentido de influir en la elaboración y regulación del nuevo orden constitucional (Krischke, 1990; Teixeira, 1992; Soares, 1993). Mientras tanto, lejos de darse por resuelta, la relación de los movimientos sociales con el universo de la ley reabre el difícil problema de su eficacia para garantizar e universalizar los derechos. La capacidad de los grupos sociales de hacer uso de sus prerrogativas es muy distinta, los beneficios sociales son distribuidos de modo desigual según el poder de resistencia y presión de los grupos más organizados, las garantías no se generalizan (Braga y Barreira, 1991; Soler, 1992) y, como muestra José Eduardo Faria (1993), el juego de fuerzas se proyecta completamente en las interpretaciones no convergentes y mucho menos unitarias de principios legales y en la "aplicación selectiva" de códigos y leyes, según las alteraciones de los distintos grupos e intereses implicados en su capacidad de articulación, conflicto y resistencia.

Entre una sociedad atravesada por conflictos específicos y demandas no generalizables y un orden legal también él asimétrico en la garantía de los derechos y prerrogativas, se configura una dinámica política que corre el riesgo de producir una "geometría variable de derechos" según las diferencias en el poder de negociación de los grupos implicados. Y ello dramatiza enormemente la cuestión social en un país en el que las transformaciones y modernizaciones ocurren a un ritmo avasallador, sin que hayan sido garantizados los principios básicos de igualdad civil y los niveles mínimos de igualdad social; en un país de enormes disparidades, cuyas carencias sociales son tan grandes como diversas, según las regiones y grupos afectados y en el que partes importantes de la población están al margen de los escenarios organizados del conflicto.

Y es eso lo que está en juego en las tendencias en curso de segmentación del mercado de trabajo y precarización de los vínculos de trabajo. En el contexto del reordenamiento global de la economía, los nuevos patrones tecnológicos y nuevos imperativos de productividad y organización productiva están dando lugar a una heterogeneización de las relaciones de trabajo que aumenta la distancia entre las ganancias de las diversas categorías y reactiva la tradición del corporativismo sindical por el poder diferenciado de resistencia de las categorías más preparadas para la defensa de sus intereses, bendiciendo las desigualdades en la distribución de beneficios y garantías laborales (Faria, 1993). La llamada flexibilización de las normas contractuales está produciendo una segmentación jurídica, que ya es una realidad en las prácticas de terciarización y de subcontratación, que lleva a muchos al peor de los mundos -un mundo en el cual no existen las garantías (ya precarias por definición) de un contrato de trabajo regular, que se estructura al margen de las normas pactadas y beneficios conquistados en acuerdos laborales y que se fragmenta en ausencia de mecanismos estables de representación (Telles, 1994). Los nuevos requerimientos tecnológicos superponen las antiguas y persistentes desigualdades a una dualización creciente entre segmentos cada vez más restringidos de trabajadores más cualificados, más valorados y preservados en sus empleos, por un lado, y una mayoría que, por otro, no posee las habilidades exigidas por el nuevo patrón productivo, transitando entre el desempleo y las alternativas precarias del mercado informal (Ribeiro, 1993). En los términos en que está teniendo lugar la desregulación del mercado de trabajo -defendida como condición de una modernización necesaria de la economía-, apenas esconde las prácticas de una privatización salvaje, con sólidas raíces en nuestra historia, que rechaza la regulación estatal y 
también el espacio social de la representación y negociación de intereses. En la formulación precisa de Maria Célia Paoli, en un mercado en el cual más de un tercio de los trabajadores está de hecho desposeído de las protecciones legales mínimas, las estrategias del capital "pasan no sólo por legalizar esa destitución de los derechos, ya ejercida en este inmenso mercado informal e incorporada en varios sectores de la producción, sino que pasan por la tentativa de extenderla a toda la fuerza de trabajo" (Paoli, 1994). En el actual escenario de desempleo creciente, de pauperización extrema, de degradación de los patrones salariales y de las condiciones de vida, la cuestión a la que se enfrenta hoy el movimiento sindical, apunta Paoli, se refiere a las posibilidades de una regulación democrática del mercado de trabajo. Sin caer en la ficción del derecho estatal, el desafío es definir derechos y sus garantías, cómo generalizarlos en un mercado cada vez más heterogéneo, atravesado por dinámicas muy diferentes y por enormes disparidades en la capacidad de los grupos obreros de hacer valer sus prerrogativas democráticas y ciudadanas.

En ese horizonte de problemas y desafíos, la cuestión de la pobreza actual se sitúa, por lo tanto, como problema propiamente político de inventar y negociar las reglas de la vida social. Pobreza, exclusión social y destitución de derechos no son, lo sabemos bien, novedades en la historia del país. Lo peculiar en los días que corren son las transformaciones que descolocan los términos en los cuales el país ha sido tradicionalmente pensado y se han formulado las alternativas de futuro, en medio de una crisis que es también una crisis de referencias y de parámetros establecidos. Y es eso lo que se evidencia en la paradoja de un sistema de protección social que, aunque renovado y reformulado a partir de la Constitución de 1988, no sólo presenta resultados mediocres sino que tampoco fue capaz, en sí mismo, de garantizar lo que ya se había conquistado, dejando a las poblaciones empobrecidas aún más vulnerables de lo que estaban al iniciarse la década de los 80 (Draibe, 1993). En ello pesaron, es cierto, los efectos de un ajuste económico salvaje, el cerco conservador que obstruyó la regulación de muchos de los derechos previstos en la ley, la devastación de los servicios públicos en el gobierno Collor, por no hablar de los corporativismos y el clientelismo de siempre. El problema mayor, sin embargo, es otro y bastante más complicado, pues "al elaborarse la agenda democrática de reformas de los programas sociales, al mismo tiempo que en el plano jurídico-institucional se ampliaron los derechos sociales y se extendió la cobertura de la protección, se produjo una profundización del foso entre los que podían acceder a los beneficios y servicios sociales y los que no; un aumento de las distancias entre los protegidos y los precaria o nulamente protegidos" (Draibe, 1993:44). Lo más desconcertante de todo ello está en el hecho de que las modificaciones constitucionales que rompieron (o prometieron romper) el perfil excluyente, estratificado y corporativo del sistema de protección social en vigor en el país durante más de cincuenta años tuvieron, en realidad, el efecto de "proteger a los ya protegidos", ya que más de la mitad de la población activa, entre el desempleo y el vínculo precario en el mercado de trabajo, permanece al margen de los beneficios sociales. El resultado, valora Sonia Draibe, es paradójico: concepciones universalistas e igualitarias de los derechos sociales son "captadas en forma privilegiada por categorías que disponen de voz, organización y fuerza" (Draibe, 1993:45), reactualizando la tradición de una ciudadanía restrictiva, asentada en la lógica de la expansión de privilegios y no de la universalización de los derechos.
Si el peso de la tradición se alimenta en esa segmentación de la ciudadanía engendrada en el interior del orden legal, las circunstancias actuales de crisis y redefinición del papel del Estado, al menos en los términos como se vienen procesando, tienden a socavar la noción misma de justicia social, por la erosión de sus principios orientadores, entre la ausencia de políticas sociales y la fragmentación social en segmentaciones múltiples atrapadas por las tendencias contemporáneas del mercado. Por un lado, la desestructuración de los sistemas públicos de previsión, salud, vivienda, educación, además de las consecuencias conocidas en el aumento de la pobreza, termina por corroer un sentido de responsabilidad pública y retira la credibilidad de la promesa de que pueda existir algo próximo al interés público encarnado en instituciones de las cuales depende la calidad de vida de las grandes mayorías. Por otro lado, sectores considerables de la población trabajadora integrada en el mercado formal ya están vinculados a sistemas privados de salud, educación y vivienda. En la valoración de Wilnês Henrique (1993), ese es un mecanismo perverso que socava la construcción de los principios de solidaridad social efectiva, en base a las diferencias de interés respecto a la calidad de los servicios y beneficios y a la capacidad de intervención. En ese escenario, propuestas de cuño neoliberal ganan terreno, insistiendo en la perspectiva de una privatización de los servicios públicos que, si se hace efectiva, institucionalizará la segmentación de la ciudadanía en base a la separación entre los que tienen condiciones de acceso a los servicios proporcionados por el mercado y aquellos que, sin condiciones de acceso regular al mercado, están destinados a los precarios servicios públicos estatales. O a la aleatoriedad de la filantropía privada.

La agenda universalista de derechos se agotó antes de haber sido implantada, concluye Sonia Draibe (1993), en función de sus contradicciones internas, de la crisis fiscal del Estado, de la ofensiva neoliberal $y$, también, de su inoperancia frente a una pobreza creciente y que exige, hoy, criterios selectivos y focalizados en la formulación de programas de asistencia y políticas compensatorias para los grupos más vulnerables. Sin embargo, tal vez el problema pueda ser planteado en otros términos, pues lo que parece estar en cuestión no son propiamente los principios universalistas de los derechos, sino el marco político en el que fueron formulados, en el presupuesto de una unidad y uniformidad de la acción del Estado capaz de compensar los efectos perversos del mercado y de las asimetrías en la posiciones. El hecho es que, junto a una pobreza de raíces seculares y de una pauperización engendrada por una crisis económica prolongada y por la precariedad de los servicios sociales básicos, las transformaciones en curso en la economía están produciendo lo que la literatura especializada llama "nueva pobreza", que escapa a las soluciones conocidas y formuladas en los términos de políticas redistributivas y compensatorias, pues éstas tienen por presupuesto exactamente lo que parece estar dejando de ser plausible, o sea, la integración regular en el mercado de trabajo. Pero eso también significa reconocer que la cuestión social no existe de forma unívoca, pues es multifacética en el orden de sus causalidades y también muy diferente según regiones, ciudades y grupos sociales afectados.

Es esa nueva configuración de la cuestión social la que está enmarcando el debate actual, iluminando las difíciles relaciones entre acumulación y derechos, economía y equidad y desarrollo y calidad de vida. Ecuaciones complicadas, que no se reducen a maquinaciones de fórmulas económicas y soluciones técnicas, 
pues exigen, entre Estado y mercado, foros públicos de representación y negociación que puedan afirmar los derechos como parámetros en el reordenamiento de la economía y de la sociedad, acogiendo a actores diversos en las negociaciones en torno a los usos de los recursos públicos de los cuales dependen la economía y la sociedad, en el horizonte de propuestas para la descentralización y democratización del Estado (Pacheco, 1993; Ribeiro, 1993; Dowbor, 1993; Daniel, 1994). Más que del agotamiento de un sistema de protección social inspirado en el modelo del Welfare State, como sugiere Sonia Draibe (1993), lo crucial tal vez sea la ruptura de un patrón burocrático de formulación y gerencia de políticas sociales, alejado de escenarios propiamente políticos de representación y negociación que establezcan los términos de los compromisos y las responsabilidades públicamente acordados, en torno a las soluciones sustentables en las diversas áreas de intervención social.

Los dilemas actuales de la ciudadanía son construidos -y así retomamos la discusión inicial- en torno a un diagrama inédito de problemas, entre la dinámica de una sociedad atravesada por demandas de justicia siempre particulares y no universalizables en las formas de la ley, la fragmentación y la exclusión social generadas por las tendencias contemporáneas del mercado y de una segmentación jurídica e institucional que obstaculiza la generalización de los derechos más allá de los grupos integrados en las arenas formales del conflicto. Pero eso es, al mismo tiempo, lo que da una medida de las perspectivas inéditas abiertas por una sociedad emergente. Enraizada en el proceso, que ya lleva muchos años, de organización de actores colectivos, de luchas sociales y reivindicaciones de derechos, esa sociedad civil puede ser entendida como una articulación de prácticas asociativas y de representación de intereses y de interlocución pública. En su horizonte está la posibilidad de la construcción de nuevas formas de regulación de las relaciones sociales a través de los "rituales de la negociación", anclados en el terreno de los conflictos, abiertos a la pluralidad de problemas y temas emergentes que no encuentran lugar en el espacio unitario estatal, a las contingencias imprevistas del conflicto social y que dislocan el poder del Estado como árbitro exclusivo, así como amplían las fronteras de las relaciones de derecho más allá de lo que es definido como código jurídico y regla formal de la ley, reconociendo lo que los juristas llaman "pluralismo jurídico". No se trata aquí de negar el papel del Estado en nombre de las virtudes emprendedoras (en la versión liberal) o libertarias (en la versión de izquierda) de la sociedad civil. La cuestión se refiere a la posibilidad de construir, entre el Estado, la economía y la sociedad, escenarios públicos que den visibilidad a los conflictos y resonancia a las demandas sociales, permitiendo, en el cruce de las razones y valores que confieren validez a los intereses implicados, la construcción de parámetros públicos que reinventen la política en el reconocimiento de los derechos como medida de negociación y deliberación de políticas que afectan a la vida de todos.

En la esfera del trabajo, es una posibilidad que se enuncia, en acuerdos sectoriales erigidos en base a reglas pactadas de conflictos, que redefinen las relaciones entre capital y trabajo, reinventan las relaciones entre lo público y lo privado e intentan la difícil ecuación entre economía y derechos, negociando los rumbos de una modernización necesaria. Contemplando cuestiones tan diversas como salarios y relaciones de trabajo, innovación tecnológica, creación de nuevos empleos, modernización del parque productivo, políticas de cualificación y reciclaje pro- fesional, terciarización y recolocación de los trabajadores, estos últimos y los empresarios negocian cuestiones estratégicas de la reestructuración industrial, con la mediación de representantes del gobierno (Bresciani, 1994). Esos acuerdos, enfatiza Francisco de Oliveira, se orientan no sólo hacia una nueva política industrial, "sino principalmente, hacia un nuevo modo de hacer política industrial", en el que los actores colectivos organizados, sin tomar el lugar del gobierno, pueden "jugar papeles decisivos en las concepciones de políticas para el país" (Oliveira, 1993a: 5-6). En rigor, dice Oliveira (1993b), la capacidad de actuación pública de esos actores está en el núcleo de la crisis actual del Estado, que es en realidad la crisis de un patrón autoritario y burocrático de gestión política. Y este es un punto decisivo: las arenas públicas de representación y negociación no se reducen al ajuste ad hoc de intereses corporativos, precisamente porque tienen la peculiaridad de publicitar conflictos privados, universalizar reivindicaciones, forzar el reconocimiento institucional de las alteralidades y constituir actores colectivos que ya no pueden ser ignorados en las políticas y programas de Estado. Y ello redefine la racionalidad del poder y también de las prácticas empresariales, ya que Estado y empresarios son obligados a negociar con actores colectivos organizados (Oliveira, 1993b). Es en esos términos que están siendo construidas nuevas formas de representación, pautadas por el reconocimiento recíproco de los derechos y de la legitimidad de los intereses implicados.

Ese es el presupuesto, dice Oliveira, de los acuerdos sectoriales. No se trata de un pacto entre iguales. Ni mucho menos de la anulación de los antagonismos bajo la ficción de una "voluntad general unificadora”. Se trata, eso sí, de una nueva contractualidad construida en una negociación que define la medida que limita la relación conflictiva de los intereses, los beneficios relativos de las partes y el conjunto de los compromisos y responsabilidades, mutuamente acordados, en los usos de los recursos públicos de los cuales dependen los resultados del propio acuerdo. Es en ese sentido en el que esa contractualidad también redefine las relaciones entre lo público y lo privado: "lo público es una socialización de los acuerdos privados mediados por las categorías universales presentes en la constitución social, en tanto que lo privado se forma por la apropiación de riquezas públicas consentidas a condición de que se cumplan los resultados objetivados" (Oliveira, 1993a: 6-7).

En el terreno de las luchas populares, la novedad radica en las relaciones que los movimientos organizados comenzaron a establecer con los poderes municipales, desplazando prácticas tradicionales de mandonismo, clientelismo y asistencialismo a través de espacios de participación y negociación en los cuales las demandas y reivindicaciones establecen la pauta de prioridades y relevancias en la distribución de los recursos públicos, así como el orden de las responsabilidades de los actores implicados. Eso es lo que se viene realizando, al menos en algunos municipios, en las prácticas de presupuesto participativo y en los distintos foros de negociación en los que, de formas diversas y con composición variada, técnicos de gobiernos, asociaciones de vecinos, entidades civiles, representantes del Poder Legislativo, sindicatos y entidades empresariales negocian alternativas para la regulación edilicia, para la urbanización de chabolas y la construcción de viviendas populares, la creación y usos de los fondos públicos municipales destinados al desarrollo urbano y a programas sociales, propuestas de defensa o recuperación del medio ambiente; para el apoyo a la llamada economía popular, 
las posibilidades de desarrollo local y gestión de la renta, además de problemas sectoriales muy específicos, cuestiones concretas o incluso episódicas (Daniel, 1994; Baierde, 1992; Kowarick e Singer, 1993; Pacheco, 1993).

Los mecanismos de participación e interlocución pública son múltiples, algunos previstos en las Constituciones municipales, otros construidos de modo informal según circunstancias y oportunidades locales; las experiencias son muy discontinuas y desiguales en los resultados obtenidos, algunas episódicas, otras más permanentes y regulares, y en ellas no están ausentes ambivalencias derivadas de lealtades políticas locales, resistencias a las prácticas de negociación, persistencia de mecanismos clientelares tradicionales, además de las dificultades para integrar grupos sociales menos organizados y con poca experiencia reivindicativa. Al mismo tiempo, estas experiencias redefinen -o permiten redefinir- la propia regulación en las instancias decisorias del poder local. Construidas en la intersección entre Estado y sociedad, esas arenas públicas permiten volver permeable la gestión pública a las aspiraciones y demandas emergentes de la sociedad civil, retirando del Estado el monopolio exclusivo de la definición de una agenda de prioridades y problemas pertinentes a la vida en sociedad. Esto significa otro modo de construir una noción de interés público: una noción plural y descentralizada, capaz de traducir la diversidad y complejidad de la sociedad, rompiendo por eso mismo con su versión autoritaria, sólidamente enraizada en la historia política del país, como sinónimo de la razón del Estado e identificada con la imposición autoritaria de la ley.

Ello no quiere decir que el interés público sea una emanación, sin mediaciones, de la participación popular. Las demandas populares son siempre particulares, los intereses en juego son conflictivos, las soluciones formuladas en los distintos espacios de representación son parciales, existen diversas concepciones sobre la definición del interés municipal, la gestión pública tiene otras determinaciones y pasa por otras competencias, de tal forma que los conflictos de intereses y valores constituyen también una disputa en cuanto a los criterios de relevancia y pertinencia pública (Daniel, 1994). Al mismo tiempo, lo peculiar en esos espacios es la posibilidad de construcción negociada de parámetros que limiten la deliberación política, el arbitraje de los intereses implicados y la definición de los criterios para los usos de los recursos públicos. En esa mediación construida entre el Estado y la sociedad es donde, tal vez, se tenga la oportunidad de enfrentar las difíciles relaciones entre pobreza y democracia. Es el dilema propuesto por Marilena Chauí, al comentar las dificultades de la construcción de un campo democrático en una sociedad polarizada entre carencias y privilegios. Si estos últimos, por definición, no se pueden universalizar como derechos, las carencias, a su vez, son tan específicas que "no llegan a transformar demandas en intereses generales de un grupo o una clase social ni, mucho menos, llegan a universalizarse y aparecer como derechos". (Chauí, 1994:9). Escapar de esa antinomia exige la construcción de una medida pública que quiebre el reinado absoluto de los privilegios y redefina el particularismo de las carencias y de los movimientos sociales que las expresan. La definición democrática de esta medida es tarea de los espacios públicos.

Es preciso decir que esas (y otras) experiencias son muy fragmentarias y discontinuas y que las conquistas son inciertas, pues tienen lugar en un terreno minado por prácticas autoritarias y excluyentes, además de no comprender a muchos (en realidad, la mayoría) de los que se encontraban fuera de las arenas organizadas de la vida social. Al mismo tiempo apuntan -y esa es su importancia- hacia una nueva institucionalidad que se abre a espacios de representación, interlocución y negociación. Es una institucionalidad construida a través de las reglas formales o informales de la convivencia pública, en formas codificadas o no, permanentes o discontinuas pero que, de alguna manera, proyectan los derechos como parámetros que delimitan el debate sobre lo justo y lo injusto, lo legítimo y lo ilegítimo, en las circunstancias y acontecimientos que afectan a la vida de los individuos, grupos y clases e, incluso, de toda una población. Es eso, a fin de cuentas, lo que se expresó y se está expresando en movilizaciones civiles por la ética en la política, contra la violación de los derechos humanos, contra el hambre, la miseria y el desempleo.

Lejos de corresponder a un proceso lineal y armónico, es una construcción siempre hecha y rehecha en el terreno mismo de los conflictos y de los equilibrios siempre precarios entre intereses y valores en disputa. Al mismo tiempo, define un campo en el cual la utopía democrática puede ser formulada en la apuesta de que hombres y mujeres descubran el sentido del espacio público, en el que las diferencias se expresan y se representan en las prácticas de la negociación; en el que los valores circulan, los argumentos se articulan y las opiniones se forman; en el que parámetros públicos pueden ser construidos y reconstruidos como límites para el debate en torno a cuestiones relevantes. En el cual, en fin, la dimensión ética de la vida social se puede constituir en una moralidad pública que depende, por entero, de la convivencia democrática con las diferencias y los conflictos que contiene, exigiendo por eso mismo, de cada uno, en cada momento, el ejercicio de esa capacidad propiamente moral de discernimiento entre lo justo y lo injusto, cuya medida, por carecer de garantías y puntos fijos, más aún en este final de siglo en el que se desmoronan antiguas certezas, sólo puede ser construida a través de una permanente y siempre renovada interlocución.

\section{REFERENCIAS BIBLIOGRÁFICAS}

Bailerle, S.G. Um Novo Princípio Ético-Político: práctica social e sujeitos nos movimentos populares urbanos em Porta Alegre. Campinas, tese de mestrado. Unicamp, 1992.

Braga, E.M.F. e Barreira, I. (coord.) A Política da Escassez. Lutas Urbanas e Programas Sociais Governamentais. Fortaleza. Fundação Demócrito Rocha, 1993.

Bresciani, L.P. Reestruturção. Diversidade e Negociação no Mundo do Trabalho. São Paulo. Hucitec/Cedi, 1994.

Chaur, M. "Uma opção radical e moderna: democracia cultural". In: FARIA, H. (org.) Experiencias de Gestão Cultural Democrática. São Paulo. Pólis Publicações Polis nº 12), 1993.

DANIEL, C. "Gestão local e participação da sociedade". In: VILLASBoas, R. (org.). Participação Popular nos Governos Locais. São Paulo, Polis (Publicações Polis nº 14). 1994.

Dowbor, L. Governabilidade e Descentralização. São Paulo, 1993. mimeo.

DraIBE, S.M. "Qualidade de vida e reformas de programas sociais: o Brasil no cenário latino-americano” Lua Nova. São Paulo, no 31, 1993 , p. 5-47.

Ewald, F. L'etat Providence. Paris. Grasset, 1986.

Faria, J.E. O Brasil Pós-Constituinte. Rio de Janeiro, Graal. 1989. 
_ Direito e Economía na Democratização Brasileira. São Paulo, Malheiros Editores, 1993.

_ "Os direitos humanos e o dilema latino-americano ás vésperas do século XXI". Novos Estudos. São Paulo. Cebrap, nº 38, mar. 1994, p. 61-78.

Henrique, W. "As políticas sociais na crise". In: APPY, B. et alii (org.). Crise Brasileira. Anos Oitenta e o Governo Collor. São Paulo, Desep/Inca, 1993.

Kowarick, L. e Singer, A. "A experiência do Partido dos Trabalhadores na Preifeicitura de São Paulo". Novos Estudos. São Paulo, Cebrap, nº 35, 1993, p. 195-216.

KRISCHKE, P. "Movimentos sociais e democratização no Brasil: necessidades radicais e ação comunicativa". Ciências Sociais Hoje. São Paulo, Vértice, 1990.

LECHNER, N. "A modernidade e a modernização são compatíveis? O desafio da democracia latinoamericana". Lua Nova. São Paulo, no 21, 1990, p. 73-86.

O’Donnell, G. "Sobre o Estado, a democratização e alguns problemas conceituais". Novos Estudos. São Paulo, Cebrap, nº 36. jul. 1993. p. $123-146$.

Oliveira, F. de "Quanto melhor, melhor: o acordo das montadoras". Novos Estudos São Paulo, Cebrap, nº 36. 1993a p. 3-8.
_ "A prova dos nove: conflitos de classe, publicização e nova contratualidade". XVII Encontro Nacional da Associação Nacional de Pós-Graduação e Pesquisa em Ciências Sociais. Caxambu, 1993b.

PACHECO, R. "Iniciativa econômica local: a experiência do ABC". En: Lodovici, E.S. e Bernareggi, G.M. Parceria Público-Privado. São Paulo, Summus, 1993.

PAOLI, M.C. "Os direitos do trabalho e sua justiça: em busca de referências democráticas”. Revista da USP. São Paulo, 1994 (no prelo).

RibeiRo, I.C.Q. Crise da Cidade. Exclusão Social e Reforma Urbana. São Paulo, 1993, mimeo.

Santos, W.G. "Fronteiras do Estado mínimo". In: Razões da desordem. Rio de Janeiro, Rocco, 1993.

SOARES, J.A. "Lei orgânica e plano diretor. Limites politicos e novos reconhecimentos". In: NASCIMIENTO, E. e BARREIRA, I. Brasil urbano. Cenários da ordem e da deseordem. Rio de Janeiro, Notrya, 1993.

SOLER, S. "Estado e movimentos sociais: entre a conquista e a concessão". Cadernos do Ceas. São Paulo, nº 136, 1992, p. 59-69.

Teixeira, E. “Cidadanía e poder local”. Cadernos do Ceas. São Paulo. n⿳⺈ 136, 1992, p. 46-58.

Telles, V. "Pobreza e cidadania: precariedade e condições de vida". In: Martins, H. de S. e Ramalho, J.R. Terceirização, Diversidade e Negociação no Mundo do Trabalho. São Paulo, Hucitec/Cedi, 1994.

\section{RESUMEN}

En este artículo se analiza la adecuación de las instituciones políticas de la Constitución de 1988 a las diversas formas de participación surgidas en el proceso de modernización reciente de la sociedad brasileña. La alteración de los patrones tradicionales de desigualdad (tanto en plano económico como político) han dado lugar a una nueva trama de diferencias sociales ante la cual los actores reaccionan de maneras diversas. La de hoy es una sociedad más heterogénea, que presenta grandes disparidades de renta, cultura, valores y acceso a los mecanismos de representación y participación política. La autora señala las principales variables que definen la actualidad sociopolítica del Brasil en los años noventa y sus líneas de evolución.

\section{ABSTRACT}

In this article it is analyzed how the political institutions designed by 1988 Constitution fit with the different ways of participation appeared in the recent modernization process of brazilean society. The changes in the traditional patters of inequality (both in the economical and political aspects) have produced a new set of social differences with distinct reactions from the actors. Nowadays society is less homogeneus presenting great disparities of income, culture, values and access to the representation and political participation processes. The author specifies the main variables which define the brazilian sociopolitical present time in the nineties and its lines of evolution. 